www.jmscr.igmpublication.org

Impact Factor 5.84

Index Copernicus Value: 83.27

ISSN (e)-2347-176x ISSN (p) 2455-0450

crossref DOI: _https://dx.doi.org/10.18535/jmscr/v5i7.104

\title{
Closed Intramedullary Nailing in Treatment of Displaced Diaphyseal Fractures of Shaft Humerus in Adults in rural setup
}

\author{
Authors \\ Dr Kiran N. Wandile, Dr Gajanan Chintawar, Dr C. M. Badole
}

\begin{abstract}
Background: Humerus serves an important role in upper extremity functions facilitating manoeuvring of hand in space. Various modalities of treatment for fixation of shaft humerus have stood the test of time and have their own advantages and disadvantages.

Methods: A study of 35 patients of fracture shaft humerus were treated with closed intramedullary nailing using Rush nail and V nail in department of orthopaedics at Mahatma Gandhi Institute of Medical Sciences , Sewagram (Wardha), a rural hospital of central India.

Results: In this study out of 35 patients, there were 19 males and 16 females, the age ranges from 19 -65 years. Most of the fractures were at the middle third of the shaft. Transverse fracture was the most common pattern observed. Average time taken for union was around 12.7 weeks. Commonest complication was shoulder stiffness.

Conclusion: Intramedullary nailing is an effective treatment for diaphyseal humeral fractures.

Keywords: Diaphyseal humerus fracture, closed, intramedullary nailing.
\end{abstract}

\section{Introduction}

Fractures of shaft humerus are routinely seen in orthopaedic practice as result of direct or indirect injury. ${ }^{(1)}$ The interposition of soft tissue may make satisfactory reduction impossible by closed means. Fractures that are in closed proximity to either shoulder or elbow have compromised outcome. $^{(2)}$ Closed nailing has emerged as dependable modality for treatment of fracture shaft humerus. It lays stress upon preservation of fracture hematoma, intact periosteum, better circulation, minimum surgical trauma , minimum blood loss, low rate infection, short operative time and hospital stay ${ }^{(1,10)}$

Almost any diaphyseal fracture shaft can be repaired with an intramedullary nail ${ }^{(10)}$. Above all, cost factor considering the modes of fixation, encouraged us to proceed with the study. The results of surgical treatment of displaced diaphyseal fracture treated with intramedullary nailing are reported in our study.

\section{Methods}

The present study was conducted in the Department of Orthopaedics, Mahatma Gandhi Institute of Medical Sciences, Sewagram (Wardha), a rural hospital of central India. The design of study was prospective cohort study. This study included 35 patients with the diaphyseal fracture humerus and age of patient ranging from 19 to 65 years. The aim of the study was to evaluate the results of diaphyseal fractures treated 
with intramedullary Rush nail or $\mathrm{V}$ nail and to assess the clinical and radiological outcome of the same.

Patients between $19-65$ years of age were included, patients with unilateral, closed, widely displaced diaphyseal fracture humerus up to Grade-I compound were included. Patients with open fractures more than Gustillo and Anderson's grade I, pathological fracture, compartment syndrome, poor skin condition/skin disorders, any medical contraindication to surgery were excluded. A thorough examination of the affected limb with examination of the neighbouring joints was done. Special attention was given regarding the neurovascular status of the limb .Detailed general and systemic examination of the patient was done. Immediate splinting of the limb was done with plaster of Paris " $U$ " slab. These patients were subjected to radiological evaluation to know the type of fracture.

Pre anaesthetic check-up of all patients were done and taken for surgery only after the final fitness by anaesthetist, also the cardio-respiratory evaluation was done.
Patients were reviewed at twelfth post op day for the first time, suture removal is done as per the condition of wound and $U$ slab was reapplied. At the end of three months patients were recalled for follow up and $\mathrm{X}$ rays were taken. Cases were called for follow up till clinic-radiological union is achieved.

The results were graded as per Brumback et al criteria. $^{(3)}$

\section{Results}

All the patients were followed up for a minimum period of 16 weeks. Range being 3 months to 30 months and an average of 13.7 months. We analysed our results at the last follow up using the parameter of post operative resumption of functions. The results are graded as excellent, good and poor. Out of 35 patients $25(71.42 \%)$ had excellent, 6(17.14\%) patients had good and $4(12.5 \%)$ had poor results. There was no failure of treatment. Average time for radiological union was 12.7 weeks.

\section{Table no.1}

\begin{tabular}{|l|c|c|}
\hline & No. patients & Percentage \\
\hline Union & 33 & $94.28 \%$ \\
\hline Delayed union & 2 & $5.71 \%$ \\
\hline Non union & 0 & O $\%$ \\
\hline
\end{tabular}

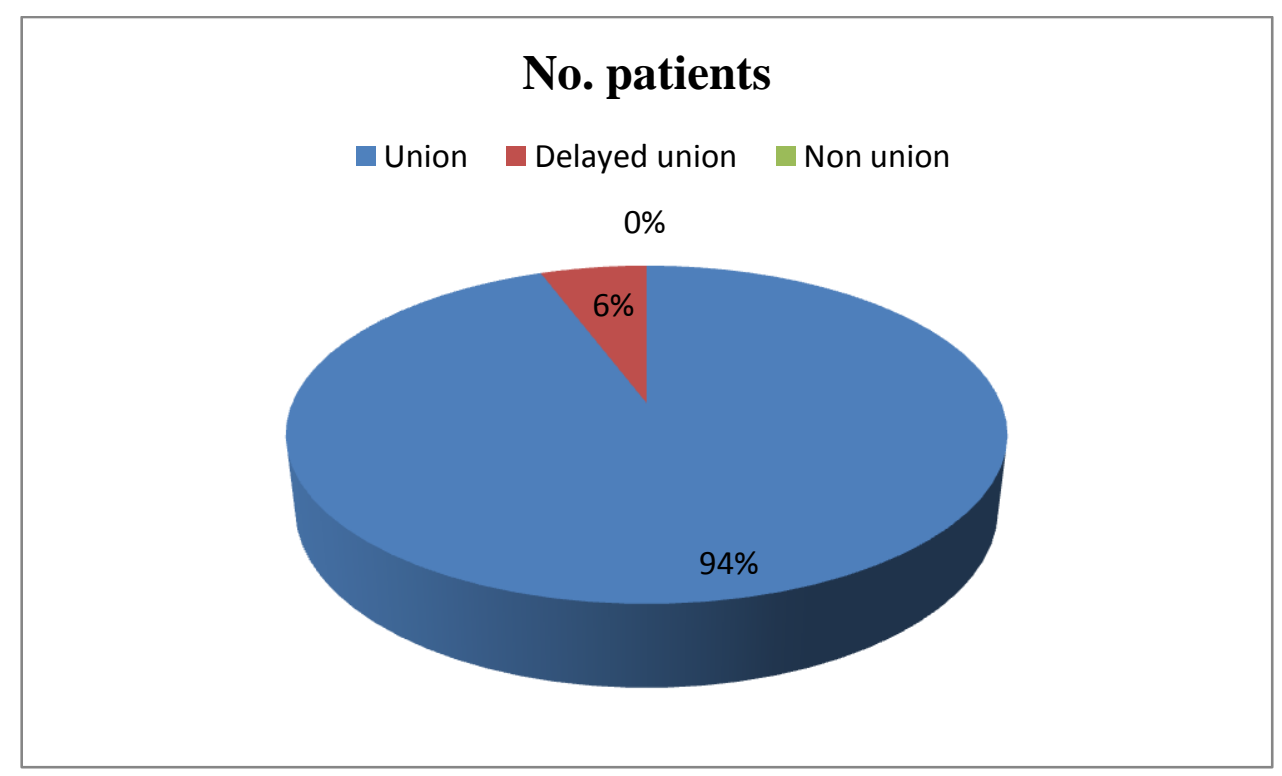



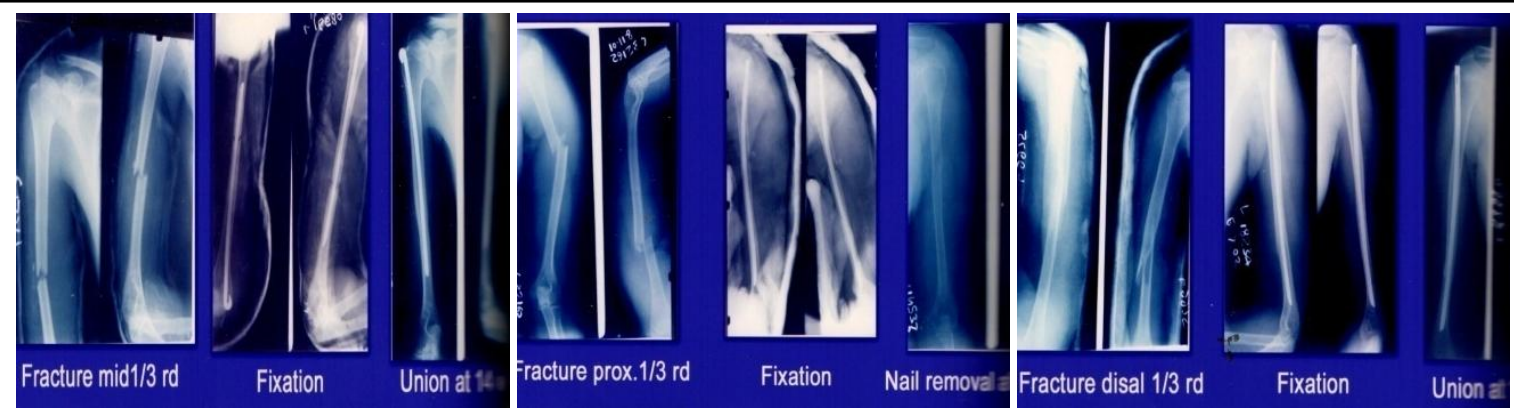

Table no.2

\begin{tabular}{|l|c|c|}
\hline Results & No. Patients & Percentage \\
\hline Excellent & 25 & $71.42 \%$ \\
\hline Good & 06 & $17.14 \%$ \\
\hline Poor & 04 & $12.5 \%$ \\
\hline Failure & 00 & 00 \\
\hline
\end{tabular}

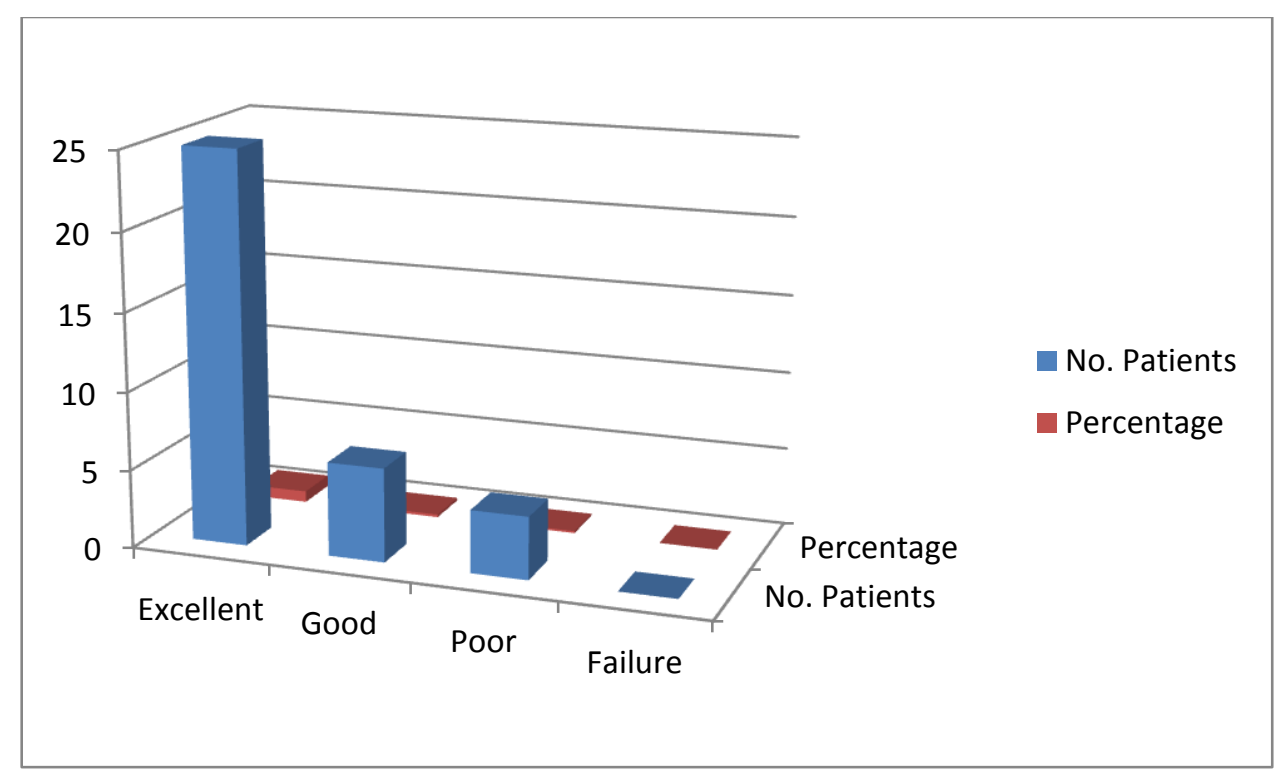

\section{Functional outcome}

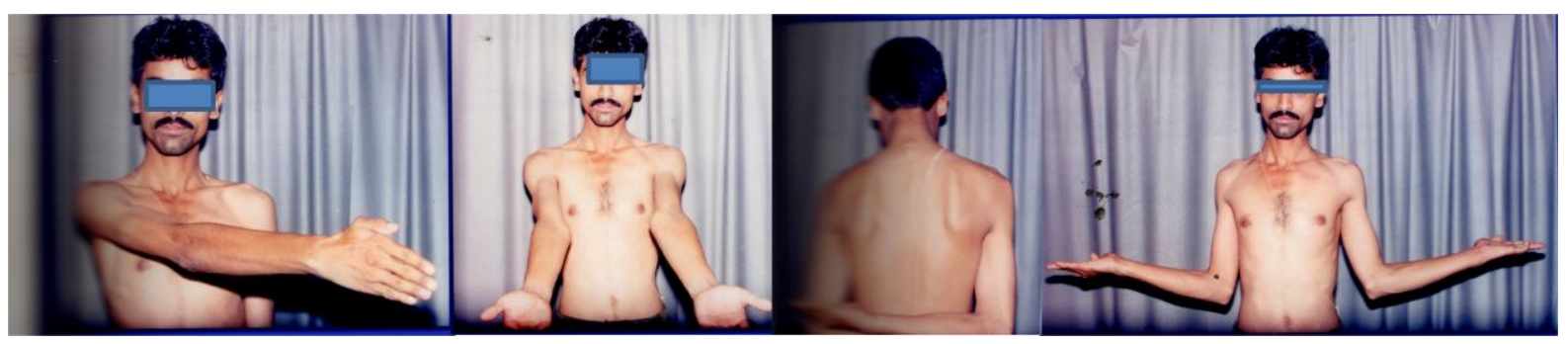

\section{Discussion}

Operative treatment of fractures of humeral diaphysis was introduced because some surgeons were dissatisfied with the existent non operative treatment methods. As with the treatment of other fractures surgeons are not always rational in their choice of treatment methods but there is some evidence that surgical stabilization of humeral diaphyseal fracture confers benefit to the patients. ${ }^{(4)}$ Until relatively recently the surgical methods employed in humeral shaft fractures were adopted from the equivalent operation in lower limb. As a result of this the surgeon who advocated humeral fracture fixation frequently based their indication for operative stabilization on those that they utilised in other areas. They 
often rationalised that the success of one particular treatment method in one body area meant that it would be successful in other areas and they based their choice of treatment modalities on this type of logic rather than on analysis of prospective studies of management of humeral shaft fracture. Modern anaesthetic techniques have rendered surgery safer and this has led many surgeons to have more interest in surgical technique than in natural history of the fractures they are treating.

Opinions are still divided regarding the appropriate management of displaced diaphyseal fracture shaft humerus. Closed nailing for this fracture definitely has an upper hand in management of displaced diaphyseal shaft humeral fracture over open procedures and closed reduction and cast application methods.

A closed displaced diaphyseal fracture with little or no communication is an ideal patient suited for closed intramedullary nailing, however it is possible to fix the fracture of proximal and distal third also by this technique.

The present study group consisted of 35 patents of which 19 males and 16 females making males more predominant. This finding of male predominance co relates with the studies of Rastogi et al. ${ }^{(5)}$ And pankovich et $\mathrm{al}^{(6)}$.

The average age in our study was 36.7 years, 2040 years age group being most prone for vehicular and industrial accidents. This finding is consistent with the study of Rastogi et al, ${ }^{(5)}$ foster et al ${ }^{(7)}$.

Fall on outstretched hand was the commonest modes in injury $(51.43 \%)$ followed by vehicular accidents (37.14\%) as has also been observed by Stern at $\mathrm{al}^{(8)}$.

Closed Nailing is favoured technique for fixation of simple and grade I compound fractures. We have fixed $31(88.75 \%)$ simple fracture and $4(11.25 \%)$ Grade I compound fractures using this technique. The study is consistent with most of the studies done by other authors Stern et al ${ }^{(8)}$, Rush and Rush ${ }^{(9)}$,and Rastogi etal. ${ }^{(5)}$

Most common fracture geometry was transverse fracture $(57.14 \%)$ followed by oblique fracture $(25.71 \%)$.

\begin{tabular}{|l|c|c|}
\hline Fracture geometry & Present study & Brumback et al $^{(3)}$ \\
\hline Transverse & $20(57.14 \%)$ & $30(47.61 \%)$ \\
\hline Oblique & $09(25.71 \%)$ & $14(22.2 \%)$ \\
\hline Comminuted & $06(17.15 \%)$ & $03(4.76 \%)$ \\
\hline Segmental & 00 & 00 \\
\hline
\end{tabular}

Middle third of diaphysis was the most common site of injury.

We used Rush nail in 13 patients and V nail 22 patients. $\mathrm{V}$ nails have the ability to control rotational stresses ${ }^{(5)}$. Three point fixation is achieved in case of rush nails, by inserting slightly curved nail into the straight humerus and entering the bone at an angle of 20-40 degrees from the longitudinal axis of humerus this controls rotation and prevent proximal migration. ${ }^{(9)}$

In our study average period of radiological union was 12.7 weeks comparable to Brumback et $\mathrm{al}^{(3)}$ was 10.5 weeks and Stern et al ${ }^{(8)}$ was 13.2 weeks. Various complications are noted in our study like shoulder stiffness, impingement syndrome, delayed union, nail bending also seen by Stern et $\mathrm{al}^{(8)}$.

\section{Conclusion}

Closed intramedullary nailing using rush nails and $\mathrm{v}$ nails is better alternative to open procedures and cast application methods. Using proper size nail, properly placing the nail and achieving three point fixations we can get excellent results with this methods.

\section{References}

1. Cananle ST. Fractures of Shoulder Girdle arm and forearm. In Cambells operative orthopaedics Ed 9St.Louis, Mosby:1998 vol 3, 2296-2309.

2. Rockwood CA, Bucholz RW, Green DP, Heckman JD. Fractures of shaft of humerus. In Rockwood and greens fracture in adults. Ed 4Philadelphia LippincottRaven publisher's 1996 vol 1,843-869.

3. Brumback R, Bosse J, Poka A, Burgess A, Intramedullary stabilization of humeral shaft fractures in patients with multiple trauma. JBJS (Am)1986:68-A:961-969. 


\section{JMSCR Vol||05||Issue||07||Page 24935-24939||July}

4. Apley AG, Rowley DI. Fixation is fun . JBJS(B)1992;74 B:486-487.

5. Rastogi S, Chandra H, Satyanand S, Jain S.Treatment of diaphyseal fractures of long bones by closed intramedullary nailing. Ind .J Orthp1987; 21(1) 44-47.

6. Hall R,Pankovich A. Ender nailing of acute fracture of the humerus .JBJS (AM)1987;69A:558-567.

7. Foster R, Dixon G, Bach A, Abbleyard R ,Green T. Internal fixation of fractures and non union of humeral shaft. JBJS (AM); 67A:857-864.

8. Stern P, Mattingly D, Pomeroy D, Zenni E, Kreig J. Intramedullary fixation of humeral shaft fractures. JBJS(AM) 1984;66A:639-646.

9. Rush LV,Rush HL. Evaluation of medullary fixation of fracture by longitudinal pin. Clin.Orthop. 1986;212:429.

10. Kuntchner GB. The kunchner method of intramedullary fixation. JBJS(AM )1958;

40A:17-26. 